\title{
Identificação de Possíveis Influenciadores Digitais em Fóruns de Discussão em Cursos a Distância
}

\author{
Identification of Possible Digital Influencers in Discussion Forums in Distance Courses
}

\author{
Thainá Paes da Justa Silva 1 (i) orcid.org/0000-0002-6907-5604 \\ Crystiano José Richard Machado ${ }^{1}$ (id) orcid.org/0000-0002-7186-4450 \\ Alexandre Magno Andrade Maciel 1 (i) orcid.org/0000-0003-4348-9291 \\ ${ }^{1}$ Escola Politécnica de Pernambuco, Universidade de Pernambuco, Recife, Brasil, \\ E-mail do autor principal: Thainá Paes da Justa Silva tpjs@ecomp.poli.br
}

\section{Resumo}

Este artigo apresenta a problemática de identificação de indivíduos com maior potencial de influenciar comportamentos e ações de outros utilizadores em ambientes de Educação a Distância, com o intuito de auxiliar o docente na otimização o aprendizado coletivo. Diversos trabalhos acadêmicos têm sido desenvolvidos para analisar a interação entre indivíduos e identificar padrões de comportamento coletivo. Nestas pesquisas, destacam-se os resultados obtidos através uso das Redes Complexas. Por outro lado, o estudo sistemático de indivíduos com maior potencial de influência em redes sociais em Ambientes Virtuais de Aprendizagem ainda é considerado um campo de pesquisa acadêmico pouco comentado. Neste contexto, um fórum de discussão pode ser o equivalente a uma rede social, e os integrantes que obtém destaque podem ser o equivalente aos indivíduos influenciadores. Este trabalho apresenta uma alternativa computacional para identificar os possíveis influenciadores através de seus comentários nos fóruns de discussão realizados em cursos a distância.

Palavras-Chave:Educação a distância, Influenciador Digital, Fórum de Discussão, Redes Complexas.

\begin{abstract}
This article presents the problem of identifying individuals with the highest potential to influence the behavior and actions of other users in Distance Education environments in order to assist the teacher in optimizing collective learning. Several academic works have been developed to analyze the interaction between individuals and to identify patterns of collective behavior. In these surveys, the results obtained through the use of Complex Networks stand out. On the other hand, the systematic study of individuals with the highest potential for influence on social networks in Virtual Learning Environments is still considered an academic field with little comment. In this context, a discussion forum can be the equivalent of a social network, and the members who get prominence can be the equivalent of influencing individuals. This work presents a computational alternative to identify possible influencers through their comments in the discussion forums held in distance courses.
\end{abstract}

Key-words: Distance Education, Digital Influencer, Discussion Forum, Complex Networks. 


\section{INTRODUÇÃO}

O Ensino a Distância (EAD) tem se tornado cada vez mais presente no cotidiano acadêmico, em especial no ensino superior, o que pode ser observado através dos relevantes índices de crescimento registrados para esta modalidade de ensino. De acordo com o Censo do Ensino Superior de 2018 um em cada cinco estudantes matriculados no ensino superior utiliza a modalidade de ensino EAD [1]. Ainda segundo pesquisas do censo em 2017 o número de concluintes em cursos de graduação presencial teve aumento de $0.9 \%$ em relação a 2016 , enquanto que a modalidade a distância aumentou $9.3 \%$ no mesmo período [2]. Essa disparidade se deve, dentre outros fatores, ao número de alunos que encontram no EAD maior flexibilidade para realizar atividades e baixos custos para quem busca o diploma. Por conta desta crescente demanda, o investimento em ferramentas que promovam a interação no aprendizado à distância faz-se cada vez mais necessário, de modo a incentivar a permanência do aluno nos Ambientes Virtuais de Aprendizagem (AVA).

Nesse sentido, os AVA têm assumido papel de destaque no cenário acadêmico, uma vez que oferecem vários recursos e ferramentas para serem utilizados como apoio a interação. Estes instrumentos contribuem de forma a viabilizar a comunicação síncrona e assíncrona entre professores, tutores e alunos que participam de cursos de EAD [3]. Segundo o Censo EAD Brasil, um dos recursos mais utilizados nos AVA é o fórum de discussão, ferramenta adotada em $87,2 \%$ dos cursos a distância no Brasil [1]. Por meio dos fóruns de discussão os alunos têm a chance de expor suas dúvidas, de se aprofundar nos conteúdos, e os professores de repassar o conhecimento de forma coletiva e dinâmica, além de propor novas discussões acerca de temas vistos em aulas online.

Com as discussões nos fóruns, alguns alunos se destacam por causa de comentários que dão espaço a novas discussões ou visualização de pontos de vistas ainda não abordados. Neste sentido, inspirar opiniões e auxiliar no desenvolvimento coletivo dos demais participantes são algumas das importantes características em indivíduos com maior potencial para serem considerados influenciadores digitais, os quais são pessoas que se destacam nas redes sociais e que possuem a capacidade de mobilizar um grande número de seguidores, pautando opiniões e comportamentos [4]. De acordo com essa definição, ao considerarmos a existência de utilizadores com 118 estas características nos AVA, a identificação dos mesmos pode representar uma otimização do processo de ensino-aprendizagem através do aprendizado coletivo. Através destes influenciadores, por exemplo, o professor terá um auxílio para obter tópicos futuros com maior relevância e a oportunidade de aprimorar a abordagem de ensino, onde o incentivo de determinado aluno pode manter a discussões 'vivas' e o fórum ativo para uma boa interação dos integrantes. Todavia, em virtude da quantidade de mensagens existente nos fóruns, da evolução dos temas abordados, e a disponibilidade de cada indivíduo, os alunos considerados influenciadores podem mudar ao longo da discussão, não sendo os mesmos desde o início até o fim do fórum.

Este trabalho tem como objetivo identificar os possíveis influenciadores digitais em fóruns de discussão de cursos à distância. O restante do trabalho está organizado da seguinte maneira: na seção 2 será apresentada a fundamentação teórica necessária para a compreensão do tema proposto; na seção 3 serão detalhados os materiais e métodos utilizados para a identificação dos possíveis influenciadores; na seção 4 são apresentados os resultados e discussões; por fim, a seção 5 apresenta as conclusões.

\section{FUNDAMENTAÇÃO TEÓRICA}

\subsection{Influenciadores Digitais}

Segundo o relatório da Hootsuite e do We Are Social [5], 42\% da população mundial são usuários ativos de redes sociais. Esta forma de interação entre pessoas já se encontra bastante difundido no meio social nos dias atuais, através das mais diversas aplicações computacionais existentes. As redes sociais ocupam um espaço crescente no discurso acadêmico, nas mídias digitais, no meio corporativo ou no senso comum. Estas redes sociais têm como finalidade configurar o espaço comunicacional tal qual representado no mundo globalizado e interconectado, no qual se produzem formas diferenciadas de ações coletivas, de expressão de identidades, conhecimentos, informações e culturas [6].

Com quase metade da população mundial conectada com o mundo virtual, segundo o We Are Social [5], muitas pessoas ganharam notoriedade com a divulgação de dicas do cotidiano, com paródias de músicas e até mesmo com vídeos virais. Isto são um dos exemplos que são considerados influenciadores digitais, utilizadores que conseguem 
disseminar sua opinião, induzir um grande número de pessoas por estarem à procura de constante informação, compartilhando suas ideias e recomendações [7].

Segundo [8], o termo influenciador digital passou a ser usado mais comumente, no Brasil, a partir de 2015. Um dos principais motivos pode estar relacionado com a entrada de novos aplicativos na esfera de produção desses profissionais que deixaram de se restringir a apenas uma plataforma.

Conforme [9], uma pesquisa apresentada no Congresso Internacional de Administração em setembro de 2017, constatou-se que um universo de 414 internautas, $91,8 \%$ seguem ao menos um influenciador digital em suas redes sociais, sendo que deste percentual, $78,5 \%$ já tiveram contato com o ponto de venda de um produto indicado pelo influenciador digital. A pesquisa apresenta também que $74,9 \%$ aceitam, às vezes, as recomendações feitas pelos influenciadores e $48,6 \%$ já adquiriram algum produto que fora indicado por influenciadores digitais.

\subsection{Redes Complexas}

O estudo de Redes Complexas (RC) é um tema interdisciplinar que abrange diversas áreas de conhecimento, tais como a ciência da computação, matemática, física, biologia e sociologia [10]. Deste modo, de acordo com [11], é possível observar que a teoria acerca das RC permite a caracterização, análise e representação dos mais variados sistemas complexos. Através de suas analogias e mapeamento estrutural, consegue-se, por exemplo, ilustrar o relacionamento entre duas entidades ou objetos.

Uma RC usualmente é representada por grafos, o qual é definido com a expressão $G(V, E)$, onde $G$ é a representação do grafo propriamente dito, $V$ representa um conjunto de vértices ou nós (nodes) e $E$ representa um conjunto de arestas (edges). Eles podem diferir segundo alguns critérios: podem ser direcionados, não direcionados ou mistos, de acordo com a direção das arestas. Além disto, as arestas podem apresentar ou não pesos, ou custo, entre um vértice e outro [12]. A Figura 1 mostra uma representação de uma RC.

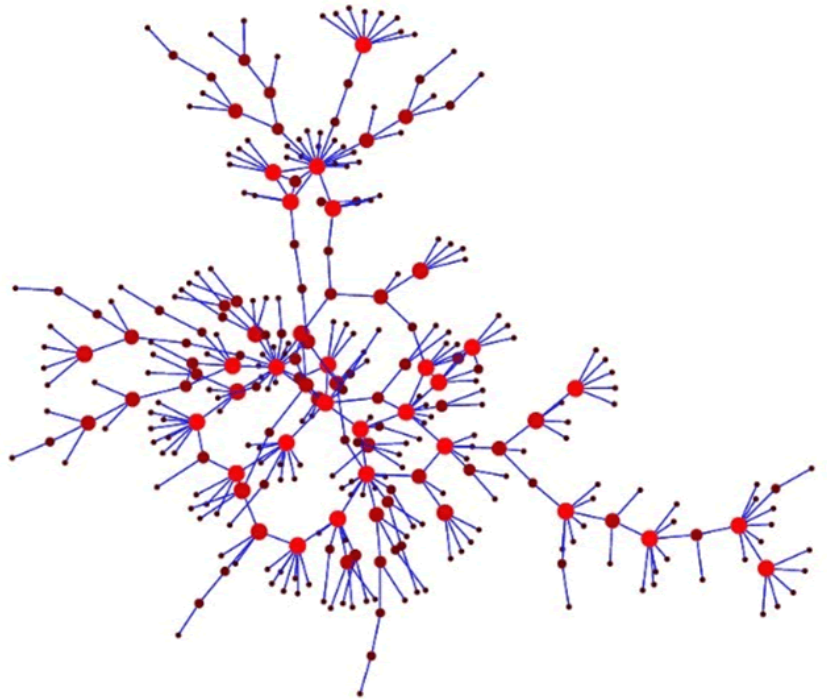

Figura 1: Representação de uma rede complexa.

Fonte: Autor (2019).

Segundo [13], além dos grafos a estrutura de uma RC pode ser representada através de uma matriz, codificando todas as arestas. Esta representação é conhecida como Matriz de Adjacência, a qual é constitui-se de uma matriz quadrada de ordem $n$ e cada elemento $A(i, j)$ representa a ligação entre o par de vértices $(i, j)$. Se o par estiver relacionado, então temos que $A(i, j)=1$, caso contrário $A(i, j)=0$. Se nessa estrutura a rede estiver codificando um relacionamento simétrico, então a matriz de adjacência será simétrica com relação a sua diagonal principal, o que significa que, neste caso, temos $A(i, j)$ $=A(j, i)$. Por outro lado, se o relacionamento for assimétrico, a matriz não será simétrica, o que significa que o elemento $A(i, j) \neq A(j, i)$. Neste caso, o grau das arestas é determinado pelo número de relacionamentos que existem com os vértices. A Figura 2 mostra um grafo de relações e sua representação em uma matriz.
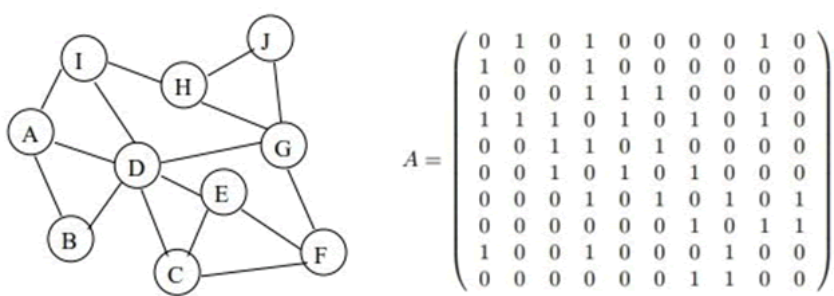

Figura 2: Grafo de relações e sua representação na matriz. Fonte: Autor (2019).

Segundo [10], as RC possuem características e propriedades que podem ser analisadas como medidas estruturais e que são frequentemente utilizadas para capturar informações topológicas 
acerca da rede. Uma das características peculiares são a centralidade (o vértice mais central) e conectividade (vértices com maior número de conexões). No exemplo de mapeamento das redes sociais para uma RC, os indivíduos podem estar representados pelos vértices, e as interações entre estes indivíduos serem representadas pelas arestas. Ainda neste contexto, a centralidade e a conectividade podem ser usadas, por exemplo, para determinar os indivíduos que melhor se relacionam com os demais ou para identificar os indivíduos mais influentes.

Em uma comparação entre as redes sociais e os fóruns de discussão, pode-se notar algumas semelhanças, como por exemplo: os alunos seguem os professores para obter conhecimento da disciplina; ou os alunos seguem uns aos outros no momento de discussões. Partindo-se desta base de conhecimento, o uso das RC apresenta potencial para permitir a análise de padrões e identificação de alunos com maiores tendências para influenciar a opinião dos demais integrantes da turma.

\section{MATERIAIS E MÉTODOS}

Como explicado na primeira seção, este artigo tem como objetivo identificar alunos que influenciam direta e indiretamente o desenvolvimento de outros estudantes em fóruns de discussão em ambientes de EAD por meio de algoritmos computacionais. Neste caso, utilizaremos Redes Complexas (RC). Por exemplo, um aluno que responde aos tópicos do professor com novos questionamentos, gerando novas discussões, de forma a conseguir respostas de outros alunos, tem a identificação realizada através das interações nas postagens geradas no fórum. Todas estas interações são mapeadas para uma RC no sentido de para construir a estrutura resultante de todas as interações ao longo do fórum. Para obter essas interações foi necessária uma base de dados com as postagens de diversos fóruns e para utilizá-las nos grafos realizou-se um tratamento dos dados existentes na base, tornando possível obter resultados satisfatórios a curto prazo.

\subsection{Materiais}

Para a realização deste experimento, foi necessária uma base de dados com postagens de diferentes fóruns. Os dados utilizados nesta pesquisa foram coletados de turmas EAD do curso de Licenciatura em Pedagogia. As postagens foram extraídas de fóruns associados às temáticas abordadas em disciplinas do $1^{\circ}$ e do $5^{\circ}$ período. Foi necessário um tratamento mínimo dos dados, através da filtragem dos conteúdos extraídos e da rotulação das colunas para cada característica identificada. Após este processo de tratamento, foi possível extrair e construir sub tabelas para serem utilizadas na a construção do algoritmo.

Primeiro, foi construída uma lista com os dados da tabela original, na qual foi possível examinar a dinâmica do fluxo de discussão. Para os dados utilizados nesta pesquisa, foram consideradas as colunas id_post, parent e userid. Em seguida, com a ajuda dos filtros, foram criadas quatro listas adicionais para compreender como era interação entre os integrantes do fórum. As listas foram determinadas a partir da presença ou não do professor e das postagens principais. Por exemplo, uma lista poderia dar origem a uma sub tabela contendo todas as postagens com todos os integrantes e outra poderia ter apenas as postagens secundários e a interação do professor com os alunos. Em uma das postagens selecionadas, foi observado que uma postagem de resposta ao tema principal continha cerca de 10 respostas e nelas apresentou-se uma boa base para temas que poderiam ser abordados no futuro. A Tabela 1 mostra as colunas presentes na tabela.

Tabela 1: Colunas presentes na tabela.

\begin{tabular}{l|l}
\hline \multicolumn{1}{c|}{ Variável } & \multicolumn{1}{c}{ Descrição } \\
\hline ID_POST & Identificação da postagem \\
\hline ID_DISCUSSION & $\begin{array}{l}\text { Identificação da postagem que deu } \\
\text { origem ao fórum }\end{array}$ \\
\hline PARENT & Relação de resposta a outras postagens \\
\hline USERID & Identificação do usuário fez o comentário \\
\hline CREATED & Período foi feito a postagem \\
\hline SUBJECT & Título do fórum \\
\hline POST & Conteúdo da postagem \\
\hline COURSE & Identificação do curso do fórum \\
\hline TITLE_FORUM & Título utilizado no tópico do fórum
\end{tabular}

Com isso, foi possível observar a viabilidade do algoritmo e que as sub listas seriam utilizadas para a construção de uma matriz, onde seriam retirados os pesos de cada vértice, simbolizando quantos replays uma postagem tinha; e para a construção dos arrays de entrada para a construção da RC. A Figura 3 mostra a representação em forma de matriz. 
$\mathrm{M}_{1}=\left[\begin{array}{llllll}0 & 1 & 0 & 0 & 0 & 0 \\ 1 & 0 & 1 & 1 & 1 & 1 \\ 0 & 1 & 0 & 0 & 0 & 0 \\ 0 & 1 & 0 & 0 & 0 & 0 \\ 0 & 1 & 0 & 0 & 0 & 0 \\ 0 & 1 & 0 & 0 & 0 & 0\end{array}\right] \quad \mathrm{M}_{2}=\left[\begin{array}{llll}0 & 1 & 0 & 0 \\ 1 & 0 & 1 & 1 \\ 0 & 1 & 0 & 0 \\ 0 & 1 & 0 & 0\end{array}\right]$

Figura 3: Representação em forma de matriz.

Fonte: Autor (2019).

A matriz M1 representa as respostas em relação a postagem 22047 e a matriz M2 representa as respostas em relação a postagem 24076, ambas foram originadas a partir do tópico principal.

\subsection{Métodos}

O algoritmo foi desenvolvido na linguagem de programação Python e tem como objetivo construir um grafo com topologia estrela, baseando-se na teoria das RC apresentadas na segunda seção deste artigo, que mostra quais postagens têm mais respostas, podendo assim identificar os possíveis influenciadores.

No início de sua construção, a entrada seria a própria tabela de dados, em que seria necessária a identificação das colunas principais dentro do código ou a construção de novas tabelas. Com essa opção, seria utilizado o Pandas, esta biblioteca é a principal ferramenta em Python para manipulação de grandes conjuntos de dados, possuindo diversas estruturas de dados personalizadas, que possibilitam o tratamento de dados de forma ágil [14]. Então, com essa biblioteca, seria possível extrair e adicionar novos itens para realizar os testes. Entretanto, por causa do tamanho da tabela (cerca de 7.000 linhas no total e, utilizando os filtros, que poderiam chegar a conter 630 linhas); o Pandas não apresentou um resultado proveitoso e mostrou que poderia atrasar o trabalho a ser realizado.

Por fim, o algoritmo foi construído utilizando como entrada um array de triplas, onde o primeiro item é o identificador da postagem, o segundo é o identificador da postagem que o utilizador respondeu, e o terceiro é a quantidade de respostas que aquele post obteve (os pesos). Para melhor visualização foi necessário colocar a postagem principal no centro do grafo, pois seu peso sempre excedia o dos outros e ele seria quem originária a postagem das outras respostas. A Figura 4 mostra um exemplo de ligação de postagens.

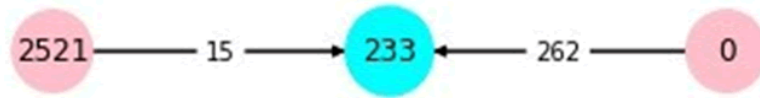

Figura 4: Exemplo de ligação de postagens.

\section{EXPERIMENTOS}

Com as sub tabelas e as matrizes prontas, foi possível a construção dos arrays de entrada e, com isso, a construção dos grafos. Vale ressaltar que as tabelas utilizadas excluíam a postagem principal e davam maior prioridade aos comentários feitos pelos alunos, pois o professor deveria incentivar a interação entre os alunos e interferir quando necessário, de modo a proporcionar a troca de informação entre os estudantes.

No primeiro experimento, foram utilizados quatro fóruns propostos para a turma de primeiro período. Nestes fóruns foi possível notar que a interação entre os alunos era quantitativamente boa, mas que algumas vezes dependiam do momento em que a postagem foi realizada. Em um dos fóruns, as postagens com mais comentários eram as mais atuais, enquanto em outro uma postagem "antiga" era a que possuía o maior peso.
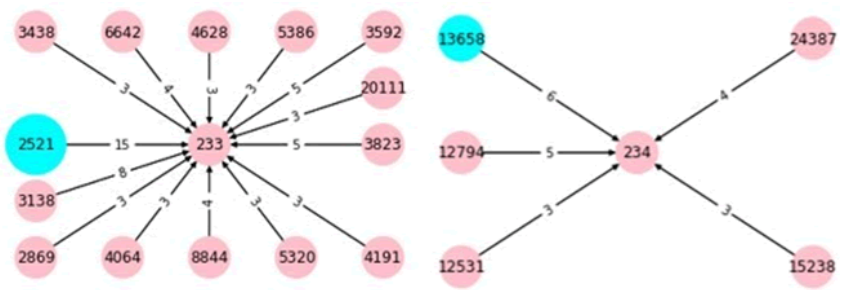

Figura 5: Grafos dos fóruns 233 e 234.

Fonte: Autor (2019).
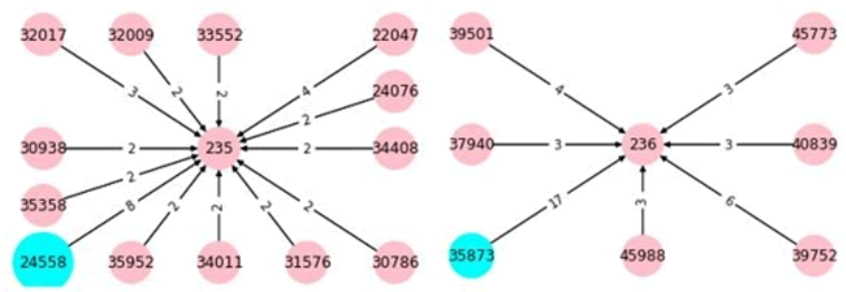

Figura 6: Grafos dos fóruns 235 e 236.

Fonte: Autor (2019).

Porém, mesmo com a diferença de tempo na apresentação do fórum, em três deles um aluno conseguiu destaque em todos os seus comentários. Mesmo não possuindo a postagem mais comentada, ele conseguia se destacar entre as postagens que mais tinham respostas. Desta forma, foi possível a criação do parâmetro que deveria levar em consideração qual aluno teve a postagem com maior peso em todos os fóruns. Este poderia ser considerado um influenciador de opinião.

No segundo experimento, foram utilizados dois fóruns de outra disciplina do mesmo período, nos quais cada um teria em torno de 190 postagens. No 
primeiro fórum, foi possível notar que o número de usuários interagindo aumentou e que, mesmo com a diferença de tempo, as postagens antigas tinham mais destaque que as novas. Também foi possível perceber que os alunos procuravam participar das discussões e compartilhar suas opiniões utilizando as respostas dos colegas como base.
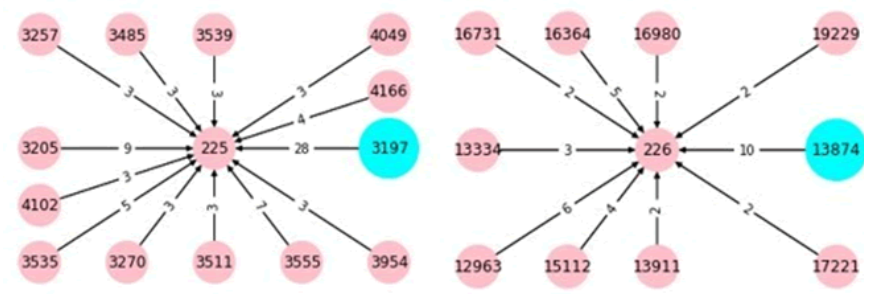

Figura 7: Grafos dos fóruns 225 e 226.

Fonte: Autor (2019).

No experimento, foi possível observar que as postagens com peso igual a 1 eram realizadas, na maioria das vezes, por um determinado aluno, apresentando a possibilidade da criação de outro parâmetro que levava em consideração um aluno que incentiva os outros a continuarem participando através de comentários construtivos, colocando em dúvida se o comentário feito é válido, abrindo novos pontos de discussões relacionados ao que foi dito. Ele tem o potencial de influenciar os outros a continuar comentando nos fóruns e apresentar um novo tópico ainda não abordado durante as aulas.

A partir disso, foram determinados dois parâmetros para identificação dos influenciadores: a quantidade de comentários em suas postagens e se eles incentivam os demais usuários a participarem da discussão. O resultado do primeiro experimento permaneceu o mesmo e no segundo, o aluno que ajudou a criar o segundo parâmetro foi o terceiro que possuía um potencial de se tornar um influenciador.

\section{CONCLUSÕES}

A solução deste artigo oferece um algoritmo que auxilia no reconhecimento dos influenciadores e dá abertura para entender como essa influência pode ajudar os demais alunos ao longo do curso. No primeiro experimento, foi observado que era necessário levar em consideração o conjunto dos fóruns para determinar quais alunos eram considerados potenciais influenciadores. Também deveria ser levado em consideração o conteúdo do comentário realizado, pois alguns comentários com três respostas eram explicando pontos que não ficaram claros no principal ou eram comentários com pouco conteúdo, por exemplo comentários como 'Concordo' ou 'Interessante'.

No segundo experimento, foi possível notar que existiam alguns alunos que estavam presentes na disciplina do primeiro experimento, e que eles procuravam interagir com a turma para manter as discussões ativas até a finalização do fórum. Esses alunos ganharam destaque, pois conseguiam citar temas relacionados a outras disciplinas, mas que se encaixavam no contexto apresentado no fórum reforçando que era preciso observar o seu conteúdo para estabelecer a característica de possível influenciador.

Também foram realizados experimentos com turmas do quinto período, porém foi observado que os fóruns não tinham o mesmo nível de participação como os períodos anteriores. As postagens com a maior quantidade de respostas variavam de 3 a 4 comentários e nestas apresentavam dúvidas e respostas a elas. Embora não tenha sido realizado um estudo sobre o fato, é preciso considerar que em muitos cursos a carga de estágio é solicitada entre o quarto e o sexto período, muitos dos integrantes poderiam ter uma rotina conturbada, impossibilitando de pesquisar mais sobre o tema quando irão apresentar seu comentário ou de ler o posicionamento dos colegas, dentre outros possíveis fatores.

Então, foi concluído que a RC resultante de uma discussão ajuda na visibilidade das interações, e se for realizada a comparação dos resultados pode-se notar qual aluno tende a fazer o papel de influenciador. Porém, o algoritmo tem uma melhor utilização em disciplinas dos primeiros períodos pois os alunos tendem a ter uma maior participação nos fóruns no início do curso.

Como trabalhos futuros, pretende-se incluir neste algoritmo a possibilidade de identificar os estudantes que foram caracterizados como influenciadores e que ainda estejam presentes em disciplinas ativas, como forma de fornecer a informação para o docente em tempo real. Além disto pretende-se investigar o impacto dos influenciadores como forma de prever o aprendizado dos demais estudantes.

\section{REFERÊNCIAS}

[1] ABED. Censo EAD.br. 2018. Disponível em: http://abed.org.br/arquivos/censo digital e ad 2018 portugues.pdf. Último acesso em: $11 / 07 / 2019$. 
[2] INEP. Censo da Educação Superior, Notas Estatísticas 2017. Disponível em: http://download.inep.gov.br/educacao superior/ censo superior/documentos/2018/censo da edu cacao superior 2017-notas estatisticas2.pdf. Último acesso em: 11/07/2019.

[3] RODRIGUES, L. R.; MACIEL, A. M.; CARVALHO, E. C. Desenvolvimento de um assistente virtual integrado ao moodle para suporte a aprendizagem online. Simpósio Brasileiro de Informática na Educação, 2014.

[4] SILVA, C. R. M.; TESSAROLO, F. M. Influenciadores digitais $e$ as redes sociais enquanto plataformas de mídia. Congresso Brasileiro de Ciências da Comunicação, 2016.

[5] WEARESOCIAL. Digital in 2018: Worlds's Internet Users Pass the 4 Billion Mark. Special Report. Disponível em: https://wearesocial.com/blog/2018/01/globaldigital-report-2018>. Último acesso: 11/07/2019.

[6] MARTELETO, R. M. Redes Sociais, Mediação e Apropriação de Informações: situando campos, objetos e conceitos na pesquisa em Ciência da Informação. Tendências da Pesquisa Brasileira em Ciência da Informação, v. 3, n.1, p. 27-46, 2010.

[7] MARIANO, A. M. Tornando-se um Digital Influencer: Um Estudo dos Fatores que Influem em sua Concepção. XXVI Congresso Internacional AEDEM, 2017.

[8] KARHAWI, I. Influenciadores digitais: conceitos e práticas em discussão. Revista Communicare, v. 17, p. 46-61, 2017.

[9] GASPAROTTO, A. P. G.; FREITAS, C. O. de A.; EFING, A. C. Responsabilidade civil dos influenciadores digitais. Revista Jurídica Cesumar, v. 19, n. 1, p. 65-87, 2019.

[10] METZ J. et al. Redes Complexas: conceitos e aplicações. Relatório Técnico do ICMC, 2017. Disponível em: http://repositorio.icmc.usp.br/bitstream/handle/ RIICMC/6720/Relat\%c3\%b3rio\%20T\%c3\%a9cnic o_290 2007.pdf? sequence $=3$. Último acesso: $11 / 07 / 2019$.
[11] LOPES, F. M. Redes Complexas de expressão gênica: síntese, identificação, análise e aplicações. Tese de Doutorado. Universidade de São Paulo, 2011.

[12] GABARDO, A. C. Análise de redes sociais: uma visão computacional. Novatech Editora, Edição 1, 2015.

[13] FIGUEIREDO, D. R. Introdução a redes complexas. In: de Souza AF Jr, Meira W (eds) Atualizações em Informática. 2011, PUC-Rio, pp 303-358. Capítulo 7.

[14] RIBAS, W. A.; NODA, E.; MARQUES, D. BigPy: um Sistema WEB para captura, tratamento e visualização de dados de defesa do consumidor utilizando Python. Trabalho de Conclusão de Curso. - Instituto Federal de Educação, Ciência e Tecnologia de São Paulo, 2018. 